\title{
Lithium Diffusion in Copper
}

\author{
Rico Rupp,,$^{\dagger}$ Bart Caerts, ${ }^{\ddagger}$ André Vantomme, ${ }^{\ddagger}$ Jan Fransaer, $^{\S}$ and Alexandru Vlad*, ${ }^{\dagger} \odot$ \\ ${ }^{\dagger}$ Institute of Condensed Matter and Nanosciences, UC Louvain, Place Louis Pasteur 1, B-1348 Louvain-la-Neuve, Belgium \\ ${ }^{\ddagger}$ Institute for Nuclear and Radiation Physics, KU Leuven, Celestijnenlaan 200d, B-3001 Leuven, Belgium \\ ${ }^{\S}$ Department of Materials Science, KU Leuven, Kasteelpark Arenberg 44, B-3001 Leuven, Belgium
}

\section{Supporting Information}

\begin{abstract}
Copper is the conventional, broadly applied anode current collector in lithium-ion batteries, because $\mathrm{Li}$ does not form intermetallic alloys with $\mathrm{Cu}$ at room temperature. Fast diffusion and trapping of lithium in copper were, however, suggested in the past, and the involved diffusion mechanisms are still not clarified. By using three complementary methods, we determine grain boundary and lattice diffusion of lithium in copper. We show that indiffusion into copper is possible not only from metallic lithium deposits at the surface but also from a $\mathrm{Li}^{+}$-containing electrolyte. Lattice diffusion $\left(D_{0}=\right.$ $\left.3.9 \times 10^{-9} \mathrm{~cm}^{2} / \mathrm{s} ; E_{\mathrm{a}}=0.68 \mathrm{eV}\right)$ and grain boundary diffusion $\left(D_{0}=1.5 \times 10^{-11} \mathrm{~cm}^{2} / \mathrm{s} ; E_{\mathrm{a}}\right.$ $=0.36 \mathrm{eV}$ ) are found to be 13 orders of magnitude lower than previously published. Furthermore, for practical Li-ion battery considerations, lithium trapping in copper current collectors, which relies heavily on operating temperature and morphology, is discussed.
\end{abstract}

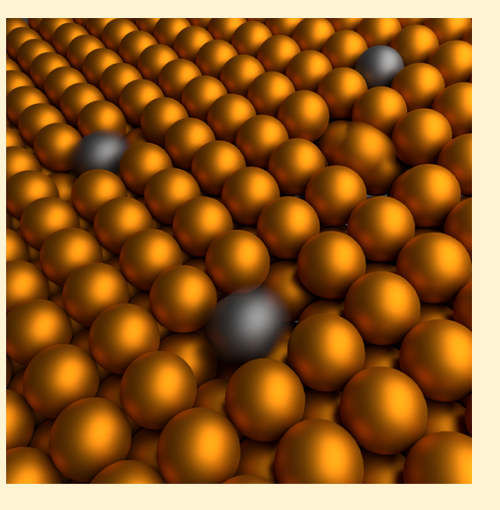

$\mathrm{L}$ ithium-ion batteries (LIBs) were commercialized as secondary cells by Sony in 1991, and the commercial use of primary lithium batteries reaches back to the 1970s with first experimental work done in the early 20th century. ${ }^{1}$ However, many seemingly basic mechanisms involving lithium are still disputed. This includes lithium diffusion phenomena within certain components of newly developed cells or even the most commonly used cells. Considering secondary LIBs, electrolytes and active electrode materials require a high diffusivity of lithium ions to ensure fast charging and discharging. Current collectors, on the other hand, are ideally inert to avoid reactions that could degrade the cells rapidly and have no tendency to incorporate lithium (ions) to prevent capacity loss during cycling of the cells. Whether a metal is inert with respect to lithium can generally be judged from its binary phase diagram with lithium. ${ }^{2}$ Only a few metals are supposed not to form intermetallic alloys with lithium at room temperature, which could happen at the anode side of the battery at low potentials versus $\mathrm{Li}^{+} / \mathrm{Li}$. These inert metals include copper, ${ }^{3}$ nickel, ${ }^{4}$ titanium, ${ }^{5}$ magnesium, ${ }^{6}$ and iron.

Due to this inertness, its electrochemical stability at the required potentials, and its good processability and high conductivity, copper is the common choice as the current collector on the anode side. However, the generally accepted binary phase diagram also shows an apparent solubility of $\mathrm{Li}$ in $\mathrm{Cu}$ of $>13$ atom \% at room temperature. ${ }^{3}$ While this value is open for debate, as will be discussed later, assuming its validity could lead to the assumption that $\mathrm{Cu}$-even without forming intermetallic alloys-exhibits non-negligible diffusion and subsequent trapping of lithium. High diffusion rates of $\mathrm{Li}$ in $\mathrm{Cu}$ were previously reported in general ${ }^{8,9}$ or more specifically in copper grain boundaries. ${ }^{10-12}$ Their use as protective coatings on anode materials was therefore investigated, because protective layers with a high lithium diffusivity could drastically improve the lifetime of a battery. ${ }^{13}$ Doubts about high diffusion coefficients, however, were expressed due to severe hindrance of the lithiation of the active material if coated with a conformal copper layer with a thickness of $\gtrsim 100$ nm. ${ }^{14-17}$ These conflicting views require a quantitative determination of lithium diffusion in copper.

While the measurement of diffusion coefficients in most metals is a standard procedure, ${ }^{18}$ lithium is a special case, because it reacts with oxygen, nitrogen, or moisture in the atmosphere, makes cross-sectioning difficult due to its soft nature, and has a low melting temperature that allows rapid diffusion of other metals. To make matters even worse, there are very few experimental techniques that can determine $\mathrm{Li}$ depth profiles. To the best of our knowledge, the only direct experimental quantification of the lithium diffusion coefficient in copper was communicated by Suzuki et al. by using a bipolar electrochemical cell, whereby a diffusion coefficient of $10^{-7}$ to $10^{-6} \mathrm{~cm}^{2} / \mathrm{s}$ at room temperature was measured. ${ }^{11}$ Gruen et al. estimated the diffusion coefficient on the basis of a $\mathrm{Cu}_{4} \mathrm{Li}$ phase studied by Old and Trevena. ${ }^{19,20}$ The experiment was performed by alloying molten lithium with copper metal at 600 ${ }^{\circ} \mathrm{C}$ for $12 \mathrm{~h}$. The major discrepancy is that the value of $2.6 \times$ $10^{-7} \mathrm{~cm}^{2} / \mathrm{s}$ for $600{ }^{\circ} \mathrm{C}$ is of the same magnitude as diffusion coefficients reported by Suzuki at room temperature. Furthermore, even Gruen's values are expected to be overestimated, because interdiffusion, which is governed by

Received: July 11, 2019

Accepted: August 22, 2019

Published: August 22, 2019 
the high diffusivity of $\mathrm{Cu}$ in liquid $\mathrm{Li}$ at $600{ }^{\circ} \mathrm{C}$, ${ }^{21}$ was neglected.

On the basis of the inconsistencies mentioned above, we have designed and employed different techniques that are suitable for measuring small diffusion coefficients at low temperatures, namely the measurement of lithium depth profiles by time-of-flight secondary-ion mass spectrometry (ToF-SIMS) in copper metal samples after being exposed to lithium sources using three complementary protocols: (i) direct contact with metallic lithium, (ii) $0 \mathrm{~V}$ (vs $\left.\mathrm{Li}^{+} / \mathrm{Li}^{0}\right)$ polarization in a Li cation-containing electrolyte, and (iii) highenergy ion implantation of $\mathrm{Li}^{+}$into metallic copper. We were furthermore able to apply these techniques at temperatures as low as $25{ }^{\circ} \mathrm{C}$ and to separate the effect of grain boundary diffusion and lattice diffusion.

For measurement of grain boundary diffusion coefficients, polycrystalline $\mathrm{Cu}$ disks with an average grain size of $12 \pm 3$ $\mu \mathrm{m}$ were mechanically and electrochemically polished and lithium was allowed to diffuse into the sample. While single crystals allow diffusion only through the bulk of the matrix, three types of diffusion are typically considered when studying polycrystalline samples. ${ }^{22}$ (i) A-Type diffusion stands for direct diffusion of lithium from the surface into copper through the lattice (bulk) of the sample, which is the same mechanism as in single crystals. (ii) B-Type diffusion describes initial fast diffusion along grain boundaries and subsequent diffusion from these defects into the bulk. (iii) C-Type diffusion appears when diffusion along grain boundaries is the dominating effect, and in this region, it can be approximated that no lithium leaves the grain boundaries.

In the first case, metallic lithium was used as a source for indiffusion and allowed to diffuse into copper for 11 days at temperatures between 30 and $120{ }^{\circ} \mathrm{C}$ (see the Supporting Information for detailed experimental conditions). An example of the ToF-SIMS concentration depth profile of $\mathrm{Li}$ in a $\mathrm{Cu}$ polycrystal after annealing at $120{ }^{\circ} \mathrm{C}$ for 11 days is shown in Figure 1.

Because the $\mathrm{Cu}$ sample in this case is polycrystalline, the $\mathrm{Li}$ concentration profile shows several diffusion regimes, as indicated in Figure 1b. At small depths (close to the $\mathrm{Li}-\mathrm{Cu}$ interface), a mixture of A- and B-type diffusion can be observed, as schematized in Figure 1a. Diffusion in the B-type

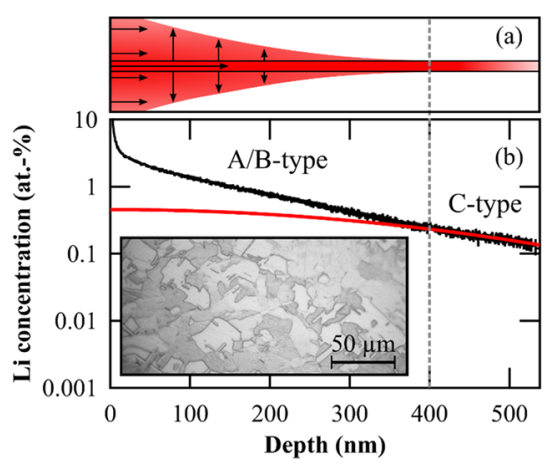

Figure 1. (a) Schematic representation of the diffusion of lithium into copper along a grain boundary. (b) Exemplary ToF-SIMS Li concentration depth profile in a $\mathrm{Cu}$ polycrystal after indiffusion from metallic lithium at $120{ }^{\circ} \mathrm{C}$ for 11 days (black curve) and exponential fit to the $\mathrm{C}$-type region, in which grain boundary diffusion dominates (red curve). The inset shows an optical micrograph of the polycrystal surface that was etched to reveal the grain boundaries. regime was described by Whipple, ${ }^{23}$ but the determination of the grain boundary diffusion coefficient in this region requires knowledge of the grain boundary width, the segregation factor of the diffusing species in the grain boundary and the bulk diffusion coefficient and was therefore not performed here. Diffusion at larger depths is governed by C-type behavior, and the logarithmic Li concentration is proportional to the square of the depth (Gaussian behavior). The concentration can be fitted by a simple Gaussian profile ${ }^{24}$ (red curve in Figure 1b), from which the grain boundary diffusion coefficient was determined. An increased $\mathrm{Li}$ concentration can furthermore be observed at the surface of the $\mathrm{Cu}$ sample $(<10 \mathrm{~nm})$ due to minimization of the surface free energy, which has previously been observed for $\mathrm{Cu}-\mathrm{Li}$ alloys, ${ }^{19}$ and due to the strong preferential reaction of lithium with oxygen or nitrogen.

To measure lattice diffusion coefficients, electrochemically polished $\mathrm{Cu}(100)$ single-crystal substrates were used instead of $\mathrm{Cu}$ polycrystals. Because lattice diffusion in metals is typically slower than grain boundary diffusion, the annealing times were adapted depending on the respective temperature. This method, however, is limited by fast diffusion of $\mathrm{Cu}$ in $\mathrm{Li}$ at elevated temperatures. ${ }^{21}$ The highest temperature at which reliable results were achieved was $160{ }^{\circ} \mathrm{C}$. At higher temperatures, the $\mathrm{Li}-\mathrm{Cu}$ interface becomes extremely rough due to interdiffusion, up to the point of severe dissolution of $\mathrm{Cu}$ into liquid $\mathrm{Li}$ at $250{ }^{\circ} \mathrm{C}$. A typical ToF-SIMS depth profile after annealing at $120{ }^{\circ} \mathrm{C}$ for 28 days is shown in Figure 2.

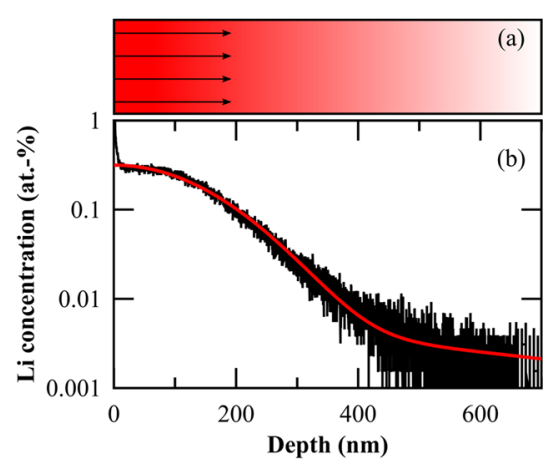

Figure 2. (a) Schematic representation of diffusion of lithium (bulk) into a copper single crystal. (b) ToF-SIMS depth profile of $\mathrm{Li}$ in a $\mathrm{Cu}$ single crystal after indiffusion from metallic lithium at $120^{\circ} \mathrm{C}$ for 28 days (black) and an exponential fit with a tail (red).

The boundary conditions in this particular case could be altered by a surface hold-up of lithium due to a thin oxide layer or limited solubility in copper $^{18}$ and were difficult to determine. The measured profiles excluding the increased surface concentration mentioned above are best described by a Gaussian function ${ }^{18,25}$

$$
C(x)=\frac{C_{0}}{\sqrt{2 \pi D_{1} t}} \exp \left(-\frac{x^{2}}{4 D_{1} t}\right)+A \exp \left(-B x^{6 / 5}\right)
$$

where $C$ is the lithium concentration, $C_{0}$ a constant related to the concentration at the boundary, $t$ the diffusion time at a given temperature, $D_{1}$ the lattice diffusion coefficient, and $x$ the penetration depth. The second term including constants $A$ and $B$ is added to account for the tail in the concentration profile. This tail can result from surface irregularities of the copper sample or fast diffusion paths along dislocations, which are both covered by addition of the exponential term and do not 
influence the calculated diffusion coefficient, as was discussed by Neumann and Lam.

Due to the temperature restrictions of the method described above, fast $\mathrm{Cu}$ diffusion in $\mathrm{Li}$, peak broadening of ionimplanted lithium in $\mathrm{Cu}$ single crystals $(\langle 100\rangle$; Alineason Materials Technology) was used to analyze the lattice diffusion coefficients in the temperature range of $180-300{ }^{\circ} \mathrm{C}$. The asimplanted ToF-SIMS profile is shown in Figure $3 \mathrm{~b}$.

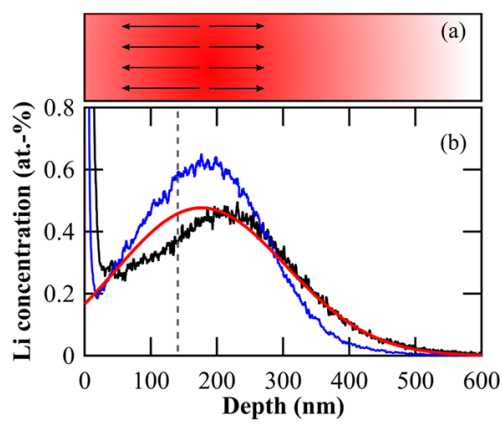

Figure 3. (a) Schematic representation of lithium diffusion in a copper single crystal after ion implantation. (b) ToF-SIMS depth profile after implantation (blue), after annealing at $300{ }^{\circ} \mathrm{C}$ for $90 \mathrm{~min}$ (black), and a weighted fit of the annealed profile (red). The dashed line marks the position of maximal induced vacancy concentration (see Figure S2 for details).

Apart from the increased surface concentration of $\mathrm{Li}$, which is also visible for this method, the as-implanted profile follows the expected truncated Gaussian and the profiles after annealing were analyzed using an analytical approach to peak broadening according to Malherbe et al. ${ }^{26}$ While the profiles after annealing show the expected peak broadening due to diffusion (see Figure $3 b$ ), a clear deviation of the profile from the expected shape is apparent. This is a result of the increased level of diffusion in the region around $140 \mathrm{~nm}$, where ion implantation resulted in the largest number of induced vacancies (see Figure S2). This effect is the so-called transient enhanced diffusion (TED). In particular, the lithium concentration toward the surface is apparently increased due to TED. To avoid artifacts from induced vacancies and from the increased surface concentration, Malherbe's analytical equation was fitted only to the right side of the profile (high depth of penetration), where a low concentration of induced vacancies is expected [based on the modeled amount of induced vacancies (Figure S2)].

Finally, the indiffusion from a $\mathrm{Li}^{+}$-containing ionic liquid was also tested, because this setup is closer to the reality in Li-ion batteries: graphite anodes operate at potentials close to $0 \mathrm{~V}$ (vs $\left.\mathrm{Li}^{+} / \mathrm{Li}^{0}\right)$, and occasional Li plating may occur under fast charge conditions, as well as underpotential deposition. Different cells were short-circuited (no induced $\mathrm{Li}$ plating) while being maintained at different temperatures (details on the setup are given in the Supporting Information). Because a low potential versus $\mathrm{Li}^{+} / \mathrm{Li}$ increases the concentration of $\mathrm{Li}^{+}$at the $\mathrm{Cu}$ surface, a larger amount of $\mathrm{Li}$ is expected within the $\mathrm{Cu}$ sample than under open-circuit conditions. The inverse was done by Gassior et al., who measured the potential of $\mathrm{Cu}-\mathrm{Li}$ alloys at high temperatures in molten salt electrolytes as a function of the $\mathrm{Li}$ concentration in the alloy. ${ }^{27}$ Limited by the thermal stability of the utilized ionic liquid, this method was applied only up to $100{ }^{\circ} \mathrm{C}$. Analysis by ToF-SIMS shows that the Li concentration depth profiles after indiffusion from a Li cation- containing electrolyte show the same behavior as when in contact with $\mathrm{Li}$ metal (see Figure S1), meaning that lithium can diffuse into $\mathrm{Cu}$ current collectors, even if no $\mathrm{Li}$ metal is deposited on the surface of $\mathrm{Cu}$. While the exact mechanism for $\mathrm{Li}$ indiffusion for this specific set of experiments is not yet clear, we presume that lithium can diffuse into $\mathrm{Cu}$ without the transfer of electrons across the electrolyte- $\mathrm{Cu}$ interface, similar to the process that Gileadi proposed for metal deposition. $^{28,29}$ Because the ionizability of $\mathrm{Li}$ is higher than that of $\mathrm{Cu}$ (the first ionization energies are 519 and $745 \mathrm{~kJ} /$ mol, respectively), lithium is present as $\mathrm{Li}^{+}$in copper (comparable to $\mathrm{Na}$ in $\mathrm{Li}$ as described by $\mathrm{Ott}^{30}$ ). The electrons that are necessary for charge neutrality are located at the top of the Fermi level of $\mathrm{Cu}$, and the charge of the $\mathrm{Li}^{+}$impurities is shielded by local changes in electron density. This is equivalent to the metal deposition process described by Gileadi, and the fact that lithium was able to diffuse into copper without any applied current supports his claims, which remains controversial.

The grain boundary and lattice diffusion coefficients calculated from all complementary experiments performed in this work are summarized in Figure 4. Following the same

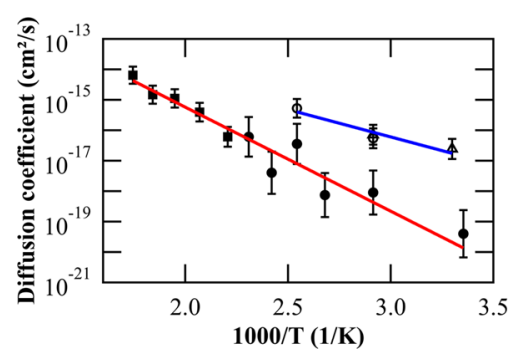

Figure 4. Arrhenius plots of lattice diffusion coefficients from singlecrystal measurements (filled symbols, red fit) and grain boundary diffusion coefficients from polycrystal measurements (empty symbols, blue fit). The data include peak broadening of ion-implanted lithium (squares), indiffusion from lithium metal (circles), and indiffusion from PYR13 with $\mathrm{Cu}$ at $0 \mathrm{~V}$ vs $\mathrm{Li}^{+} / \mathrm{Li}$ (triangles).

trend, the lattice diffusion coefficients extracted from indiffusion and $\mathrm{Li}^{+}$implantation are in good agreement with each other. This additionally confirms the validity of both methods. By avoiding the influence of interdiffusion of the two metals and any eventual surface or interface effects due to roughening or oxide layers, ion implantation leads to a smaller error. The resulting Arrhenius equations of the lattice and grain boundary diffusion are given by

$$
D_{1}=3.9 \times 10^{-9} \exp \left(-\frac{0.68 \mathrm{eV}}{k_{\mathrm{B}} T}\right) \mathrm{cm}^{2} / \mathrm{s}
$$

and

$$
D_{\mathrm{gb}}=1.5 \times 10^{-11} \exp \left(-\frac{0.36 \mathrm{eV}}{k_{\mathrm{B}} T}\right) \mathrm{cm}^{2} / \mathrm{s}
$$

The activation energy for lattice diffusion with $0.68 \mathrm{eV}$ is in excellent agreement with the value of $0.67 \mathrm{eV}$ for the vacancy diffusion mechanism obtained by Xiong et al. using ab initio calculations. ${ }^{31}$ We did not observe a curvature of the Arrhenius plot due to divacancies at temperatures below $300{ }^{\circ} \mathrm{C}$, which could however be related to the inherently low accuracy of the indiffusion experiments. The lower activation energy of 0.36 
$\mathrm{eV}$ that was measured for grain boundary diffusion results from the high defect density between grains. The room-temperature diffusion coefficients from Arrhenius fits are $1.3 \times 10^{-20}$ and $1.4 \times 10^{-17} \mathrm{~cm}^{2} / \mathrm{s}$ for lattice and grain boundary diffusion, respectively. These are 13 orders of magnitude lower than previously reported values of $10^{-7}-10^{-6} \mathrm{~cm}^{2} / \mathrm{s}^{11}$

While the diffusion coefficients provide information about the speed of $\mathrm{Li}$ uptake in $\mathrm{Cu}$, the actual amount of $\mathrm{Li}$ that can potentially be trapped in current collectors cannot be obtained from these values. The amount of $\mathrm{Li}$ that diffused into $\mathrm{Cu}$ can nevertheless be extracted from the indiffusion experiments by integration of the concentration profiles, including the increased surface concentration of lithium. The respective values for room temperature and $120{ }^{\circ} \mathrm{C}$ are listed in Table 1 .

Table 1. Masses of Lithium That Diffused into Copper during the Indiffusion Experiments at Different Temperatures and Durations, As Extracted from ToF-SIMS Depth Profiles

$\begin{array}{ccc}\text { temperature } & \text { single crystal (28 days) } & \text { polycrystal (11 days) } \\ 27{ }^{\circ} \mathrm{C}\left( \pm 3{ }^{\circ} \mathrm{C}\right) & 3 \mathrm{ng} / \mathrm{cm}^{2} & 10 \mathrm{ng} / \mathrm{cm}^{2} \\ 120{ }^{\circ} \mathrm{C} & 156 \mathrm{ng} / \mathrm{cm}^{2} & 591 \mathrm{ng} / \mathrm{cm}^{2}\end{array}$

As expected and confirmed by diffusion experiments, grain boundaries lead to a faster and higher rate of Li uptake in copper. Even though lithium was allowed to diffuse for only 11 days into the polycrystals, while diffusion into $\mathrm{Cu}$ single crystals was performed for 28 days, a 3-4-fold higher mass uptake of $\mathrm{Li}$ in $\mathrm{Cu}$ was found for the polycrystalline samples as compared to the single crystals. This gives evidence that smaller grains (and therefore more grain boundaries) lead to a higher rate of uptake of lithium.

It is worth pointing out that the commonly accepted $\mathrm{Cu}-\mathrm{Li}$ binary phase diagram is based on experiments that were conducted by Klemm et al. by using fine $\mathrm{Cu}$ powder. ${ }^{32}$ This $\mathrm{Cu}$ powder offers many grain boundaries and a large surface area where the $\mathrm{Li}$ concentration is increased, as well as an increased total amount of surface oxide with high lithium content, as compared to bulk samples with a low surface-tovolume ratio. We believe thus that the actual bulk solubility of $\mathrm{Li}$ in $\mathrm{Cu}$ is much lower than that shown in the binary phase diagram.

The polycrystals utilized here were hot-rolled and have thus a relatively large average grain size of $12 \mu \mathrm{m}$. Battery current collectors, on the other hand, are typically electrodeposited and have average grain sizes closer to $1 \mu \mathrm{m}$. We expect this to be the reason for the much larger amount of lithium $(10.6 \mu \mathrm{g} /$ $\mathrm{cm}^{2}$ ) that was found by Rehnlund et al. after 7 days at $50{ }^{\circ} \mathrm{C}$ (lithium in direct contact with copper). ${ }^{8}$ Whether the amount of trapping $\mathrm{Li}$ in $\mathrm{Cu}$ could be neglected will strongly depend on the chemistry and configuration of the anode electrodes used, as well as operation temperature. When using low-mass loading in thin film anodes, for example, lithium trapping might be found to lead to significant relative losses, especially when long lifetimes at increased temperatures are sought. Room-temperature operation, even for a typical battery lifetime, is expected to lead to minimal Li losses in typically used $\mathrm{Cu}$ current collectors. As was previously proposed by $\mathrm{Lv}$ et al. $^{10}$ and is confirmed here, the use of copper current collectors with a large grain size could be a valid method for limiting lithium losses when necessary.

\section{ASSOCIATED CONTENT}

\section{Supporting Information}

The Supporting Information is available free of charge on the ACS Publications website at DOI: 10.1021/acs.jpclett.9b02014.

ToF-SIMS measurements and determination of relative sensitivity factors, indiffusion from metallic lithium and electrolytes, and ion implantation and the influence of induced vacancies on peak broadening (PDF)

\section{AUTHOR INFORMATION}

\section{Corresponding Author}

*E-mail: alexandru.vlad@uclouvain.be.

ORCID

Alexandru Vlad: 0000-0002-0059-9119

Notes

The authors declare no competing financial interest.

\section{ACKNOWLEDGMENTS}

R.R. is a Research Fellow at the Belgian Fonds de la Recherche Scientific (FRS-FNRS). This work was supported by the FNRS-U.N011.18-DEMIST, CF-ARC (18/23-093) MICRO$\mathrm{BAT}$, the Fund for Scientific Research-Flanders, the KU Leuven BOF, and the EU Horizon 2020 program (824096, RADIATE).

\section{REFERENCES}

(1) van Schalkwijk, W. A.; Scrosati, B. Advances in Lithium-Ion Batteries; van Schalkwijk, W. A., Scrosati, B., Eds.; Springer US: Boston, 2002.

(2) Gottstein, G. Physikalische Grundlagen der Materialkunde, 3rd ed.; Springer-Verlag: Berlin, 2007.

(3) Okamoto, H. Cu-Li (Copper-Lithium). J. Phase Equilib. Diffus. 2011, 32 (2), 172-172.

(4) Predel, B. Li-Ni (Lithium-Nickel). In Li-Mg-Nd-Zr. LandoltBörnstein - Group IV Physical Chemistry (Numerical Data and Functional Relationships in Science and Technology); Madelung, O., Ed.; Springer: Berlin, 1990; Vol. 5H, p 1.

(5) Bale, C. W. The Li-Ti (Lithium-Titanium) System. Bull. Alloy Phase Diagrams 1989, 10 (2), 135-138.

(6) Nayeb-Hashemi, A. A.; Clark, J. B.; Pelton, A. D. The Li-Mg (Lithium-Magnesium) System. Bull. Alloy Phase Diagrams 1984, 5 (4), 365-374.

(7) Predel, B. Fe-Li (Iron-Lithium). In Dy-Er-Fr-Mo. LandoltBörnstein - Group IV Physical Chemistry (Numerical Data and Functional Relationships in Science and Technology); Madelung, O., Ed.; Springer: Berlin, 1995; pp 1-3.

(8) Rehnlund, D.; Lindgren, F.; Böhme, S.; Nordh, T.; Zou, Y.; Pettersson, J.; Bexell, U.; Boman, M.; Edström, K.; Nyholm, L.; et al. Lithium Trapping in Alloy Forming Electrodes and Current Collectors for Lithium Based Batteries. Energy Environ. Sci. 2017, 10, 1350-1357.

(9) Rehnlund, D.; Pettersson, J.; Edström, K.; Nyholm, L. Lithium Trapping in Microbatteries Based on Lithium- and $\mathrm{Cu} 2$ O-Coated Copper Nanorods. ChemistrySelect 2018, 3 (8), 2311-2314.

(10) Lv, S.; Verhallen, T.; Vasileiadis, A.; Ooms, F.; Xu, Y.; Li, Z.; Li, Z.; Wagemaker, M. Operando Monitoring the Lithium Spatial Distribution of Lithium Metal Anodes. Nat. Commun. 2018, 9 (1), 2152.

(11) Suszuki, J.; Sekine, K.; Takamura, T. Measurements of Li Diffusion Rate in Metal Using a Bipolar Cell in Which a Tungsten Electrode Is Used to Sense $\mathrm{Li}^{+}$Ion Concentration. Electrochemistry 2003, 71 (12), 1120-1122. 
(12) Neudecker, B. J.; Dudney, N. J.; Bates, J. B. Lithium-Free" Thin-Film Battery with In Situ Plated Li Anode. J. Electrochem. Soc. 2000, 147 (2), 517.

(13) Vlad, A.; Rupp, R. Coated Silicon Nanowires for Battery Applications. In Silicon Nanomaterials Sourcebook - Vol. I; Sattler, K. D., Ed.; Taylor \& Francis Group: Boca Raton, FL, 2017; pp 475-494.

(14) Vlad, A.; Reddy, A. L. M.; Ajayan, A.; Singh, N.; Gohy, J.-F.; Melinte, S.; Ajayan, P. M. Roll up Nanowire Battery from Silicon Chips. Proc. Natl. Acad. Sci. U. S. A. 2012, 109 (38), 15168-15173.

(15) McDowell, M. T.; Lee, S. W.; Wang, C.; Cui, Y. The Effect of Metallic Coatings and Crystallinity on the Volume Expansion of Silicon during Electrochemical Lithiation/Delithiation. Nano Energy 2012, 1 (3), 401-410.

(16) Sethuraman, V. A.; Kowolik, K.; Srinivasan, V. Increased Cycling Efficiency and Rate Capability of Copper-Coated Silicon Anodes in Lithium-Ion Batteries. J. Power Sources 2011, 196 (1), 393-398.

(17) Sandu, G.; Brassart, L.; Gohy, J. F.; Pardoen, T.; Melinte, S.; Vlad, A. Surface Coating Mediated Swelling and Fracture of Silicon Nanowires during Lithiation. ACS Nano 2014, 8 (9), 9427-9436.

(18) Neumann, G.; Tuijn, C. Self-Diffusion and Impurity Diffusion in Pure Metals, 1st ed.; Elsevier, 2008.

(19) Gruen, D. M.; Krauss, A. R.; Susman, S.; Venugopalan, M.; Ron, M. Gibbsian and Radiation-induced Segregation in $\mathrm{Cu}-\mathrm{Li}$ and Al-Li Alloys. J. Vac. Sci. Technol., A 1983, 1 (2), 924-928.

(20) Old, C. F.; Trevena, P. Reaction in Copper-Lithium System and Its Implications for Liquid-Metal Embrittlement. Met. Sci. 1981, 15 (7), 281-285.

(21) Ott, A. Interstitial-Like Diffusion of Copper in Lithium. J. Appl. Phys. 1969, 40 (6), 2395-2396.

(22) Kaur, I.; Gust, W. Grain and Interphase Boundary Diffusion. In Diffusion in solid metals and alloys; Mehrer, H., Ed.; Springer-Verlag: Berlin, 1990; pp 630-716.

(23) Whipple, R. T. P. CXXXVIII. Concentration Contours in Grain Boundary Diffusion. London, Edinburgh, Dublin Philos. Mag. J. Sci. 1954, 45 (371), 1225-1236.

(24) Crank, J. The Mathematics of Diffusion, 2nd ed.; Clarendon Press: Oxford, U.K., 1975.

(25) Lam, N. Q.; Rothman, S. J.; Mehrer, H.; Nowicki, L. J. Selfdiffusion in Silver at Low Temperatures. Phys. Status Solidi B 1973, 57 (1), 225-236.

(26) Malherbe, J. B.; Selyshchev, P. A.; Odutemowo, O. S.; Theron, C. C.; Njoroge, E. G.; Langa, D. F.; Hlatshwayo, T. T. Diffusion of a Mono-Energetic Implanted Species with a Gaussian Profile. Nucl. Instrum. Methods Phys. Res., Sect. B 2017, 406, 708-713.

(27) Gasior, W.; Onderka, B.; Moser, Z.; Debski, A.; Gancarz, T. Thermodynamic Evaluation of $\mathrm{Cu}-\mathrm{Li}$ Phase Diagram from EMF Measurements and DTA Study. CALPHAD: Comput. Coupling Phase Diagrams Thermochem. 2009, 33 (1), 215-220.

(28) Gileadi, E. Can an Electrode Reaction Occur without Electron Transfer across the Metal/Solution Interface? Chem. Phys. Lett. 2004, 393 (4-6), 421-424.

(29) Gileadi, E. The Enigma of Metal Deposition. J. Electroanal. Chem. 2011, 660 (2), 247-253.

(30) Ott, A. Impurity Diffusion in Lithium. Z. Naturforsch., A: Phys. Sci. 1970, 25, 1477-1483.

(31) Xiong, Z.; Shi, S.; Ouyang, C.; Lei, M.; Hu, L.; Ji, Y.; Wang, Z.; Chen, L. Ab Initio Investigation of the Surface Properties of $\mathrm{Cu}(111)$ and Li Diffusion in Cu Thin Film. Phys. Lett. A 2005, 337 (3), 247255.

(32) Klemm, W.; Volavsek, B. Zur Kenntnis Des Systems LithiumKupfer. Z. Anorg. Allg. Chem. 1958, 296 (1-6), 184-187. 